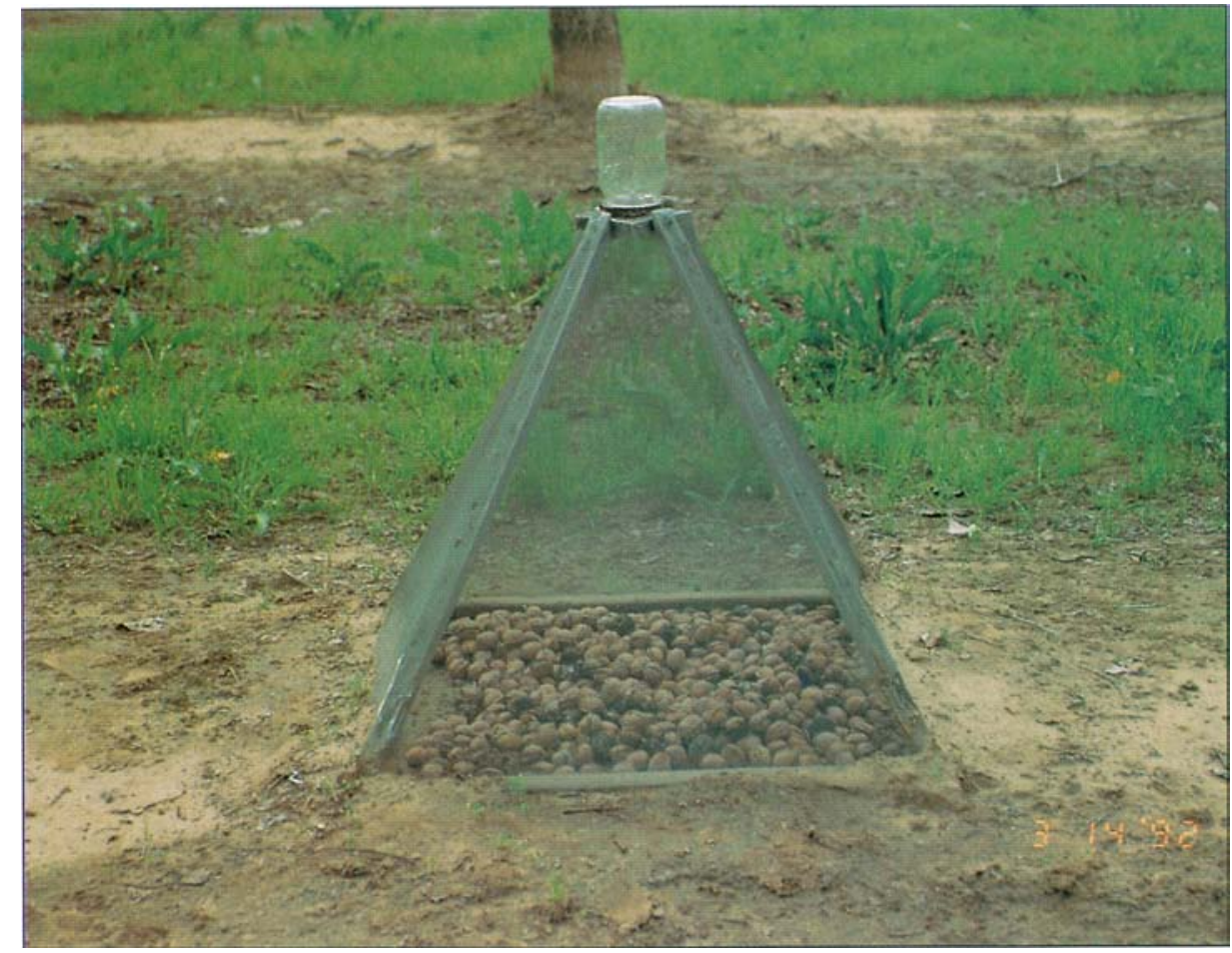

Trap apparatus for collecting emerging navel orangeworms (berm treatment).

\title{
Shredding "mummy" walnuts is key to destroying navel orangeworm in winter
}

\section{G. Steven Sibbett $\square \quad$ Robert A. Van Steenwyk}

\section{Winter orchard sanitation is a major component of navel orangeworm (NOW) control in walnuts. "Mummy" nuts remain- ing in the trees shelter overwin- tering NOW. Once nuts are re- moved from the trees, shredding to destroy the protective shell en- sures maximum NOW mortality.}

Navel orangeworm, Amyelois transitella (Walker), is one of the most devastating pests of walnuts grown in California. Damage results when its larvae infest nuts following hull split before harvest. Economic loss to the walnut industry was estimated at \$12 million in 1990 and $\$ 9$ million in 1991.

A year-long control program is required to manage navel orangeworm (NOW). Navel orangeworm cannot infest sound, uninjured nuts during the growing season, as long as growers minimize disease, injury from insects and physical damage that would provide entry sites for infestation. Once hull split occurs, growers must harvest the crop promptly to prevent infestation. Postharvest operations call for orchard and equipment sanitation, removal of trash nuts from the huller/dehydrator and destruction of unharvested nuts to remove sites where NOW larvae and pupae can overwinter. This procedure reduces the number of overwintering NOW and the potential for infestation the following year.

Orchard sanitation is a major component of NOW management and control in walnuts. It includes shaking trees during the dormant season to remove previously unharvested "mummy" walnuts. Following shaking, nuts should be shredded to destroy the protection offered to NOW by the walnut shell.

Not all walnut growers have shredders capable of destroying the nuts and must rent or contract for this service.
Moreover, shredding is not always compatible with a grower's cultural program; that is, in cultivated orchards, uneven ground and clods can preclude complete destruction of the nuts. Other orchard floor management strategies and their effect on NOW survival within the nut (that is, laying nuts in sod or weeds throughout winter or disking mummy nuts into the soil) have not been explored until now. If such practices were proved effective in destroying overwintering NOW, growers would have more flexibility in orchard sanitation. Here, we report the results of a 2year study that evaluated effects of these orchard management practices on the survival of overwintering NOW larvae and pupae in mummy walnuts on orchard floors.

\section{Porterville experiment}

The experiment was conducted in Porterville, California, during the winter and spring of 1990-1991 and 1991-1992 in a mature 'Serr' walnut orchard with a history of economic NOW damage. Navel orangeworm infestation in mummy walnuts was estimated in the orchard each year. Each December, approximately 100 pounds of mummy nuts were collected from the orchard. Twenty random samples of 10 nuts each were chosen from the entire lot. These samples were inspected for NOW larvae and pupae to estimate the percentage of NOW infestation. In 1990-1991, 27\% of the nuts were infested with one or more NOW pupae or larvae; infested nuts had an average of $1.2 \pm 3.0$ NOW larvae and pupae per mummy nut. In 1991-1992, $30 \%$ of the nuts were infested but with fewer insects per nut, $0.3 \pm 0.4$ NOW larvae and/or pupae per mummy nut.

In 1990-1991, 250 randomly selected nuts and in 1991-1992, 500 randomly selected nuts underwent one of four treatments: (1) Nuts were placed on a weedfree 'berm' (to simulate weed-free, bare ground). (2) Nuts were placed in resident weed cover ( 3 to 4 inches high at time of placement; wet weeds were expected to rot nuts which harbored NOW). (3) Nuts were placed on the orchard floor and shredded with a flail shredder. (4) Nuts were placed on the orchard floor and disked in two directions. Each treatment was replicated four times. Thus, according to pretreatment crack-out, approximately 300 NOW larvae or pupae in 1990-1991 and 200 in 1991-1992 were placed into each replicate of each treatment.

The nuts underwent their respective treatments December 20,1990, and December 4, 1991, in the orchard where they were collected. Following treat- 


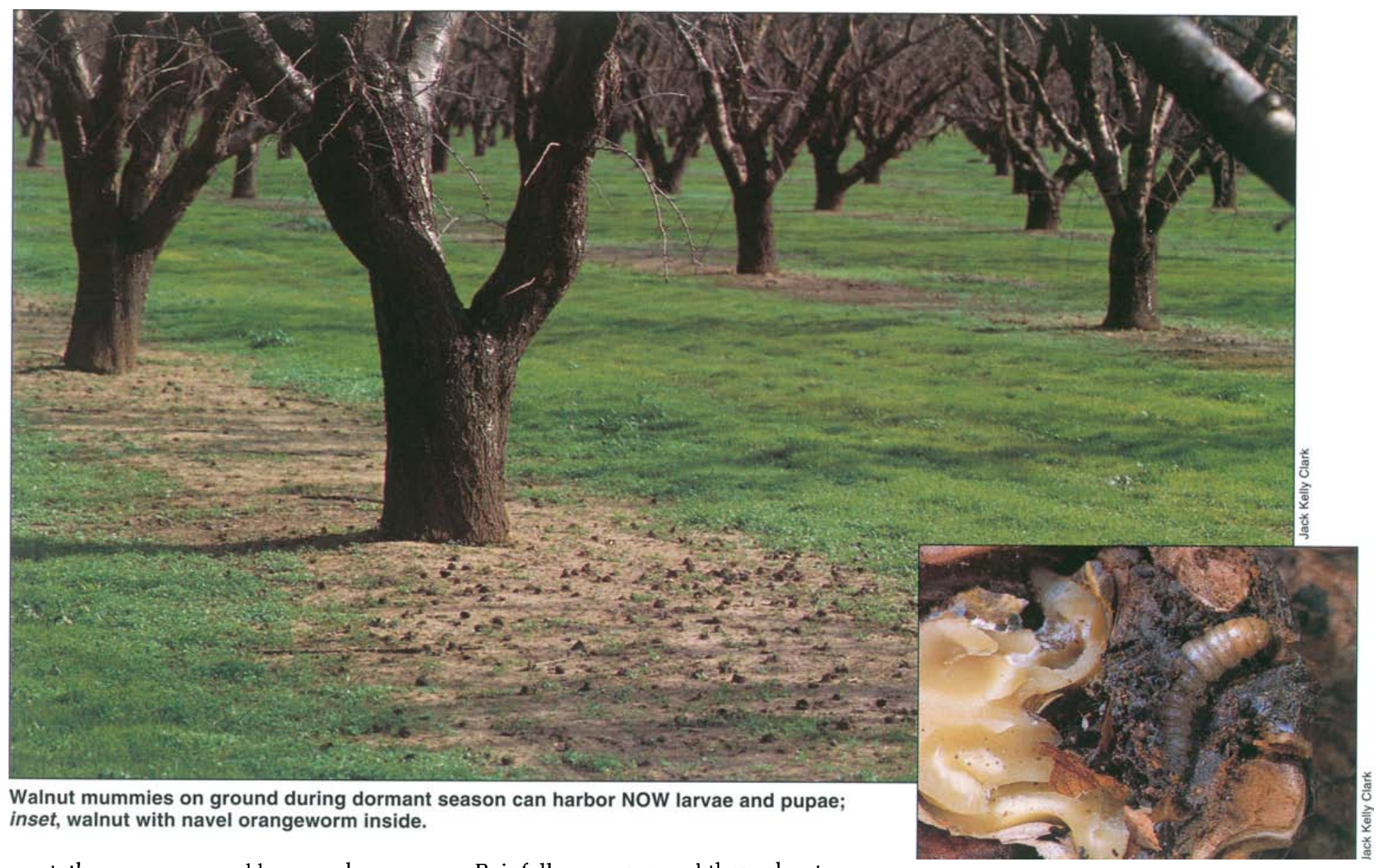

ment, they were covered by a mesh pyramid cage, $1 \mathrm{~m} \times 1 \mathrm{~m}$ square at the base and $1 \mathrm{~m}$ high. Each cage was equipped with a 1-quart canning jar affixed to the apex of the pyramid to collect adult NOW moths. Following the disking treatment and cage placement, any nuts lying outside of the cage's $1 \mathrm{~m}$ $\times 1 \mathrm{~m}$ dimensions were carefully placed under the cage in the same position relative to their depth of burial. Each cage was monitored for adult NOW emergence at 2-week intervals during the winter. Once emergence began, cages were monitored weekly for adult emergence from March 29 through June 19, 1991, and from March 11 to June 3, 1992. The average number of NOW adult moths that emerged was analyzed by ANOVA (analysis of variance) and means were separated by Duncan's multiple range test, $\mathrm{P} \leq 0.05$.
Rainfall was measured throughout the experiment. In 1990-1991, little rainfall occurred, and two midwinter irrigations were applied to simulate the 10 inches of winter rainfall the area normally receives. In 1991-1992, about 11 inches of rain fell, a more normal rainfall pattern.

\section{Laboratory emergence}

One sample of nuts, retained each year, was held under ambient laboratory conditions to observe adult NOW emergence and any parasite activity. In 19901991, 127 nuts containing approximately 150 NOW larvae and pupae were reserved to observe emergence in the laboratory; in 1991-1992, 300 nuts containing approximately 81 larvae and pupae were observed.

In 1990-1991, 36 adults emerged under ambient laboratory conditions, and in 1991-1992, 16 adults emerged, ap-

TABLE 1. Effects of various mummy nut destruction techniques on overwintering ability of navel orangeworm in walnuts

\begin{tabular}{lrccc}
\hline \hline & \multicolumn{4}{c}{ Mean no. of emerged navel orangeworm adults* } \\
\cline { 2 - 5 } Treatment & $1990-91$ & Reduction & $1991-92$ & Reduction \\
\hline Nuts placed on bare berm & $63.3 \mathrm{a}$ & $\%$ & $11.8 \mathrm{a}$ & \\
Nuts placed in weeds & $8.8 \mathrm{~b}$ & & $9.0 \mathrm{a}$ & 24 \\
Nuts double-disked & $2.3 \mathrm{~b}$ & 95 & $3.8 \mathrm{~b}$ & 68 \\
Nuts shredded & $.0 \mathrm{~b}$ & 100 & $.3 \mathrm{C}$ & 97 \\
\hline "Numbers followed by the same letter in columns are not significantly different at P $\leq .05$ DMRT.
\end{tabular}

proximately $24 \%$ and $20 \%$, respectively, of the NOW population. No parasites emerged from the laboratory samples in either year.

\section{Effects of orchard floor}

1991. Significantly higher NOW moth emergence occurred when mummy nuts were placed on the bare, weed-free berm than when placed in weeds, disked or shredded (table 1). Mummy nuts placed on the bare berm yielded an average of 63.3 adult NOW moths per replication. This compares with an average of $8.8,2.3$ and $0 \mathrm{NOW}$ adult moths emerged from mummy nuts placed in weeds, disked or shredded, respectively. Percent recovery from the initial population was $21 \%, 3 \%$ (97\% reduction), $1 \%$ ( $95 \%$ reduction) and $0 \%$ (100\% reduction), respectively.

1992. As in 1991, the highest emergence occurred when mummy nuts were placed on the bare, weed-free berm. However, unlike 1991, no significant difference in emergence was detected between nuts placed on the bare berm or in weeds. Adult NOW emergence from nuts placed on the bare berm or in weeds was significantly higher than when nuts were disked or shredded. Average moth emergence from shredded nuts was significantly lower than those disked (table 1). Nuts placed on the bare 
berm or in weeds averaged 11.8 and 9.0 moths per replication, respectively. Disked nuts yielded an average of 3.8 moths per replication. Emergence from shredded mummy nuts was 0.3 (one nut was found intact following the shredding treatment). Percent recovery from the initial population was low $-5.9 \%$, $4.5 \%$ ( $24 \%$ reduction), $1.9 \%$ (68\% reduction), and $0.2 \%$ ( $97 \%$ reduction) for berm, weeds, disked or shredded, respectively, compared with 1991. It is unknown why this discrepancy occurred. In the 1991-1992 winter, rainfall was relatively normal, and temperatures were more moderate than in 1990-1991, when a severe freeze occurred in midDecember following placement of the nuts in the orchard. Interestingly, under laboratory conditions, NOW adult emergence was relatively similar each year.

These results are unlike those obtained for almond, which has a relatively soft shell compared with walnut. Little NOW survival occurred in mummy almonds allowed to remain in a weedy cover throughout winter. Disking also resulted in considerably better NOW mortality in almond than walnut. The thicker walnut shell apparently offers considerably more protection than does the almond shell.

\section{Conclusions}

Winter orchard sanitation is essential to NOW management in walnut orchards. However, simply removing mummy nuts from the trees does not destroy overwintering larvae and pupae and prevent subsequent adult emergence. Our data show that adult NOW readily emerge from intact nuts shaken from trees and allowed to remain on a dry, weed-free orchard floor. Shredding mummy nuts following their removal from the trees essentially eliminates all NOW survival. Disking nuts into the soil, or allowing nuts to remain in a weedy cover reduces emergence but does not eliminate it; $a$ few nuts in each situation probably remain exposed and relatively dry, allowing NOW to survive.

Our data offer little flexibility in managing mummy nuts to eliminate NOW overwintering, once nuts are shaken from trees. Shredding remains the best method for ensuring maximum destruction of larvae and pupae in a walnut sanitation program.

\section{G. S. Sibbett is Farm Advisor, Tulare}

County, and R. A. Van Steenwyk is Extension Entomologist, Department of Entomology, UC Berkeley.

Domestic, world market growing ...

\section{Grape juice concentrate emerging as a sweetener in juices, food products}

Dale Heien $\square \quad$ Ray Venner

\section{The domestic and world market for grape juice concentrate is growing. We discuss several op- tions that may enable the San Joaquin Valley's grape industry to capture a larger share of this growth market.}

Grape juice concentrate, an emerging growth industry, is used in making grape and multifruit juices and in sweetening food products. Production in California increased to approximately 462,000 tons in 1991, accounting for $28 \%$ of the 1991 San Joaquin Valley crush (grape districts 12, 13, and 14, see map). The concentrate, produced by heating grape juice under a vacuum to remove water, competes with apple and other fruit juice concentrates as well as sugar, mainly on a price basis.

San Joaquin Valley grape growers generally view concentrate as a market for surplus grapes, just as wine was once a market for grapes not marketed as table grapes or raisins. Over time the wine market has relied increasingly on wine-specific varietal grapes and on grapes grown in California's coastal areas. Today, the grape juice concentrate market is filling the surplus grape market role. Just as grape production changed in response to wine industry demand, grape production for concentrate could become a primary market for San Joaquin Valley growers. This article examines the prospects and problems in making this transition.

\section{The concentrate market}

Grape juice concentrate is diluted into single-strength grape juice and multifruit and sparkling juice. It also sweetens jams and jellies, yogurt, frozen fruit desserts, cereals, cookies and other bakery products. Fruit concentrates are replacing table sugar and corn syrup as many consumers perceive fruit concentrate as a healthier sweetener. Consumers favorably view products labeled "no sugar added." In 1989, when white grape juice concentrate sold for $\$ 4.50$ a gallon, the costs of grape juice concentrate and table sugar were similar. Now, grape juice concentrate is slightly more expensive.

Sparkling juice sales in the U.S., totaling 37.3 million gallons in 1989, are growing $15 \%$ annually. Sales of spreadable fruits are also increasing at the same rate. Demand for products containing fruit concentrate is expected to continue.

U.S. grape juice concentrate is primarily supplied by several varieties grown in the San Joaquin Valley and by the Concord variety in New York and other northern states. Table 1 presents basic U.S. grape juice concentrate production and trade.

The price of grape juice concentrate is strongly affected by the worldwide supply of apple juice concentrate, which accounts for approximately $72 \%$ of U.S. fruit concentrate consumption. Apple and grape are close substitutes for multifruit and sparkling juices. Apple juice concentrate prices fluctuate with the level of apple juice concentrate imports and the amount of the U.S. apple crop processed into concentrate. For example, in 1991, the prices of all fruit concentrates rose substantially as fewer apples were diverted into concentrate due to fears surrounding the use of the growth regulator Alar. The price of apple juice concentrate in 1993 plummeted because of bumper apple harvests 